\title{
Editorial Review of Volume 18
}

Many of the topics in Volume 18 are long established as subjects of comparative analysis; yet our authors manage to have something fresh to say even while writing about the course of revolution, the institutions of slavery, and the nature of religious movements. Never enough in itself, novelty is nevertheless vital to good scholarship, and it is instructive to note some of the qualities common to these quite different essays. First, they eschew traditional taxonomies (thus avoiding the temptation to amputate some limbs of social action in order to stuff unidentifiable torsos into prefabricated boxes). These essays compare real behavior, not abstractions. Second, they incorporate the awareness of complexity and the sensitivity to social context that comes from having done original research. Third, they use comparison to identify new questions and to sharpen them. At this middle level, between new evidence and grand theory, comparison is especially fruitful, exposing stimulating connections for example, between the more general studies of revolution by Zagorin and Hermassi, Skocpol's analysis of social revolution (all in 18:2) and Hunt's treatment of local politics in the French Revolution and McHenry's of collective farms (18:3). If effective comparison should sharpen questions, it should also widen horizons, helping to show how immediate, local concerns become part of larger movements, how knowledge of other societies and methods can contribute to the analysis of specific cases.

One stimulus to better theory is, of course, its application to cases often neglected; Tomasson's study of illegitimacy in Iceland (18:2) says by implication much about all of Europe; and no fewer than five articles in this volume use the stimulus of growing knowledge about Africa (McHenry, Strickland, Hill, De Craemer et al., and Henige) to illuminate diverse topics that range from "traditional" institutions (like slavery) to "modernizing" efforts (at collectivization) and include a careful assessment of methods for dating events that are but vaguely remembered (through astronomical knowledge of eclipses).

The subject of most of the articles in this volume is social structure, revealed through imaginative study of social behavior: the reactions of British workers to propaganda for contraception (McLaren, 18:2), the 
social origins of saints (Goodich, 18:4), or patterns of violence and homicide in the middle ages (Becker and Hanawalt, 18:3). But there is no conflict between a focus on social structure and attention to attitudes and ideas. The prejudices of a simple science that views structure as "hard" and ideas as "soft" have disappeared from Skinner's and Mishra's interpretations of convergence and from their subsequent debate $(18: 1)$, from Strickland's analysis of kingship and slavery (18:3), or from the analysis of peasant movements in the Balkans (18:1) in which Denich, Mouzelis, and Ferguson can allow local circumstances, attitudes, and even personality their place while cautiously seeking generalizations about the relationship between the structure of peasant communities and political mobilization.

This consistent interest in the relationship of social structure, attitudes, and behavior shows clearly in the treatment of religious movements in this last issue of Volume 18. The social analysis of religion (last treated in CSSH in 17:2 by Akhavi, Gombrich, and Lane) has in fact been a frequent theme in these pages, and Shapiro's article continues his study of religious reformations (see 15:2). Perhaps the study of religion especially challenges the analyst to see society whole. The other main topic of this issue-method-nearly always an implicit concern, is less commonly explicit. There is of course no single comparative method. But just as effective comparison requires some methodological rigor, so their common interests require students of society to give careful attention to the methods they use. Each of the articles in this volume, then, is part of a larger discourse to which CSSH intends to contribute. 